\title{
Aplicação da análise SWOT - um estudo de caso em um restaurante \& peixaria na região de Várzea Grande MT
}

\author{
Application of SWOT analysis - a case study in a restaurant \& fishmonger in the \\ region of Várzea Grande MT
}

\author{
Andrey Sartori ${ }^{1 *}$, Nídia Guerra ${ }^{1}$, Rubens de Oliveira ${ }^{1}$, Anderson Vieira ${ }^{1}$, Giovani Koch $^{1}$, \\ Ederson Souza $^{1}$, Rosicley de Siqueira ${ }^{1}$, Fabricio de Moraes $^{2}$
}

\begin{abstract}
RESUMO
Neste artigo realiza-se uma análise da matriz SWOT e a elaboração de um plano estratégico através de um estudo de caso em um Restaurante \& Peixaria localizada na região do Bonsucesso em Várzea Grande/MT. A pesquisa busca apresentar as diferentes formas de usar a matriz SWOT com intuito de ganhar diferencial estratégico neste seguimento. A análise SWOT retrata que o estabelecimento seja capaz de ter uma perspectiva clara e concreta sobre quais são sua forças e fraquezas no círculo interno, e suas oportunidade e ameaças no círculo externo, essa análise os proprietários podem preparar estratégias para obter ganho competitivo e melhorar o desempenho organizacional. Os ganhos conquistados no estudo ratificaram que está analise foi essencial para auxiliar na tomada de decisão e trazer vantagens almejadas. O propósito do estudo foi atingido, uma vez que foi apresentada a matriz SWOT pode-se colaborar para a expansão e o desenvolvimento da empresa, relacionando a teoria com a aplicação do estudo de campo.
\end{abstract}

Palavras-chave: Matriz SWOT; Ambiente Interno; Ambiente Externo; Plano Estratégico.

\section{ABSTRACT}

In this article, an analysis of the SWOT matrix is carried out and a strategic plan is elaborated through a case study at the Fishmonger located in the Bonsucesso region in Varzea Grande / MT. The research seeks to present the different ways of using the SWOT matrix in order to gain strategic differential in this segment. The SWOT analysis portrays that the establishment is able to have a clear and concrete perspective on what are its strengths and weaknesses in the inner circle, and its opportunities and threats in the outer circle, consequently, this analysis the owners can prepare strategies to obtain competitive gain and improve organizational performance. The gains achieved in the study confirmed that this analysis was essential to assist in decision making and bring competitive advantages. The purpose of the study was achieved, once the SWOT matrix was exposed, it can collaborate for the expansion and development of the company, relating the theory to the application of the field study.

Keywords: SWOT Matrix; Internal Environment; External Environment; Strategic Plan

\footnotetext{
${ }^{1}$ Instuição de afiliação: FATEC SENAI MT

*E-mail: andrey.sartori@ senaimt.edu.br

${ }^{2}$ Instuição de afiliação diferente: IFMT
} 


\section{INTRODUÇÃO}

A diminuição dos custos, atributo dos produtos, recepção, local que permita bem-estar aos clientes, já não são fundamentos eficientes para assegurar a repercussão do comércio. A construção de um plano estratégico para a organização do negócio, cujos dirigentes são conscientes para indicar os procedimentos que irá gerar novas conquistas no mercado.

O Restaurante \& Peixaria pesquisado nesse artigo começou suas atividades há 23 anos, apresentando um cardápio com os tradicionais peixes do Rio Cuiabá: o Pacu e o Pintado. O Restaurante \& Peixaria dedica-se para possuir um ambiente amplo e de lazer para que as famílias possam degustar com tranquilidade, aguardando alcançar uma fatia do mercado dentro do distrito de Bonsucesso e nas redondezas onde atua.

A inexistência de um plano de desenvolvimento de longo prazo associado à falta de conhecimento dos colaborados da empresa conforme as atividades nela exercidas compõem-se na justificativa deste artigo. Por outro lado, identificou-se na empresa uma capacidade de crescimento no mercado em que está inserida que justifica estabelecer uma proposta de plano estratégico que possa reforçar o crescimento contínuo da organização.

Com finalidade de obter referências mais perceptíveis sobre a empresa à ferramenta a ser utilizado é a analise SWOT. O propósito do estudo é mencionar o quanto é útil à percepção do setor (ambiente externo) e o conhecimento do próprio estabelecimento (ambiente interno), para o desenvolvimento e avanço do negócio de pequenos restaurantes, em um mercado cada vez mais competitivo.

O intuito geral deste estudo é apresentar como o Restaurante \& Peixaria deve utiliza o plano estratégico para acatar as novas exigências e obter a liderança de mercado, captação, satisfação e rentabilidade. Tendo como objetivos específicos relatar a organização da matriz SWOT dentro do Restaurante \& Peixaria considerando seus quatro fatores e quais são os planos de ação para cada fator (Forças e Fraquezas, Oportunidades e Ameaças). 


\section{REFERÊNCIAL TEÓRICO}

\section{A METODOLOGIA CLÁSSICA DO PLANEJAMENTO}

De acordo com Serra, Torres e Torres (2004), o planejamento deve resultar da lógica estratégica, para dar espaço à agilidade, somando-se às transformações do meio ambiente e dirigindo a realização de ações planejadas. Portanto, sua formação não pode ser feita como simples exercício de planejamento. O planejamento precisará ter por base três componentes de reflexão estratégica, que contam com a análise estratégica, a formulação da estratégia, além da organização e implementação desta. As fases do planejamento estratégico podem expor algumas variações segundo os diferentes autores e suas abordagens. Oliveira (1998) põe a analise do ambiente como etapa anterior à definição da visão, missão e valores. Já Serra, Torres e Torres (2004) apresentam a visão e missão como ponto de partida do processo. Os mesmos autores indicam a seguinte metodologia (Figura 1) para o planejamento estratégico:

Figura 1 - Metodologia sugerida para o planejamento estratégico

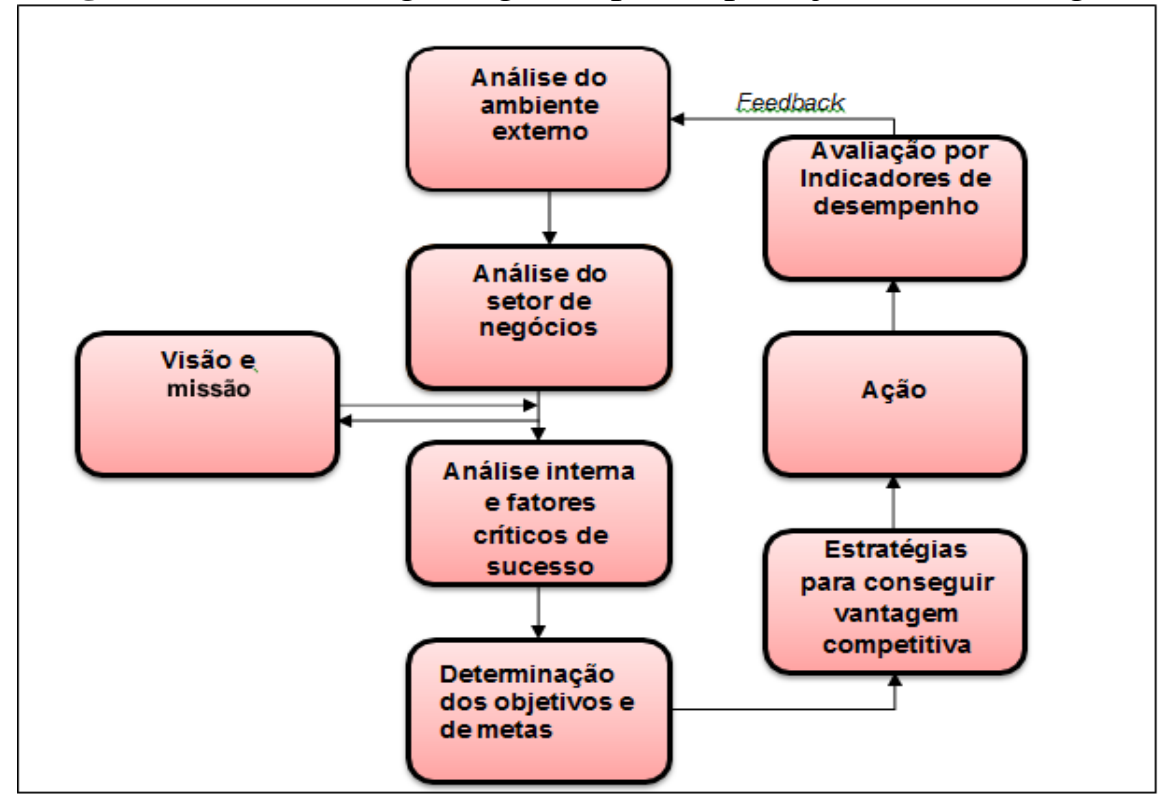

Fonte: Serra, Torres e Torres (2004)

A concepção do plano estratégico constitui-se na determinação de visão, missão e valores, na análise do ambiente interno e externo, na exposição dos fatores críticos de sucesso, nos objetivos e metas que resultam em estratégias. 


\section{PLANEJAMENTO ESTRATÉGICO}

De acordo com Drucker (1984), o planejamento estratégico refere-se de um método contínuo que sempre envolve assumir medidas novas que causam riscos, tais como: organizar as atividades necessárias à execução dessas decisões. Pois, as decisões devem ser tomadas com o máximo de dados possíveis sobre a futuridade e suas prováveis implicações, e os esforços necessários para colocar em pratica essas decisões, tende a ser organizadas de forma sistemáticas e durante todo o processo o feedback precisa ser constante.

No ponto de vista de Oliveira (1998), a empresa deve delinear, através do planejamento, mapear e focar no uso dos seus pontos fortes; identificar, eliminar ou corrigir suas fraquezas; identificar e desfrutar de oportunidades externas; mapear e evitar ameaças externas; estabelecer plano de ações. Assim, a execução do planejamento resultara em participação nas ações, uma vez que todos os funcionários conhecerão a visão, missão e valores como objetivos da empresa.

\section{VISÃO, MISSÃO E VALORES}

Conforme Serra, Torres e Torres (2004), a visão e a missão são usadas para conduzir a ideias e os valores da empresa, sendo necessário o conhecimento de suas questões fundamentais, a fim de compreender a sua diferença, que pode, parecer sutil. Segundo os mesmos autores, é apto definir a visão como o discernimento das necessidades do mercado, e os procedimentos pelos quais umas empresas podem executar. Facilita a empresa a cooperar em benefício de valores comuns, proporcionando direciona-la para a utilização de uma oportunidade. A visão deve ser coerente e gerar uma imagem clara do futuro e formar compromisso com o desempenho.

Para Serra, Torres e Torres (2004) a declaração de missão é a explicação por escrito das intenções e aspirações da organização. O objetivo de uma missão é difundir o objetivo da empresa, que está ligado a sua visão e a de todos os membros da organização, de forma a concentrar esforços para alcançar seus objetivos. A missão é a razão da existência da organização.

De acordo com Serra, Torres e Torres (2004), toda organização é um conjunto aberto, e por consequência sofre influências externas. São diversos os motivos que 
influenciam a atividade empresarial, e eles podem revelar-se como elemento substancial para reconhecimento de oportunidades e ameaças. Dessa forma, as empresas tem que se manterem atentas não apenas às habilidades específicas do seu ramo, mas observar qualquer fator que possa ter significado. A exibição a seguir traz uma relação esclarecedora de fatores externos que possui influência sobre as organizações:

Tabela 1 - Fatores que influenciam os negócios

\begin{tabular}{|c|c|}
\hline \multicolumn{2}{|r|}{ FATORES POLITICOS } \\
\hline Taxa de juros & Influência nas vendas \\
\hline Fontes de financiamento & Disponibilidade de fontes de financiamento \\
\hline \multicolumn{2}{|r|}{ Fatores econômicos } \\
\hline Inflação & Impacto no volume de vendas \\
\hline Sistemas de tributação & Influência das formas de tributação dos produtos \\
\hline \multicolumn{2}{|r|}{ Fatores tecnológicos } \\
\hline Influência da tec. na Produção & Surgimento de novos materiais \\
\hline Influência da tec. no Mercado & Desenvolvimento do produto atual \\
\hline $\begin{array}{l}\text { Influência da tec. na } \\
\text { Comercialização }\end{array}$ & Influência nos processos de armazenagem \\
\hline \multicolumn{2}{|r|}{ Fatores político-legais } \\
\hline Política internacional do Governo & $\begin{array}{l}\text { Influência de acordos internacionais no desenvolvimento } \\
\text { do mercado interno }\end{array}$ \\
\hline Regulamentação comercial & Restrições ou impedimentos à exploração do negócio \\
\hline \multicolumn{2}{|r|}{ Fatores sócio-culturais } \\
\hline Fenômenos de opinião & Influência dos meios de comunicação \\
\hline Fatores demográficos & Taxa de crescimento da população \\
\hline Fatores sociais & Ciclo de vida das famílias \\
\hline Fatores culturais & Exposição aos meios de comunicação \\
\hline
\end{tabular}

Fonte: Serra, Torres e Torres (2004)

Segundo Tavares (2010), o macroambiente possibilita os impactos mais extensos e significativos em uma organização, de onde se dirigem as oportunidades e ameaças à sua atuação. Agora as causas internas de uma organização estão relacionadas com as suas forças e com as suas fraquezas, conforme apontam Serra, Torres e Torres (2004).

\section{ANÁLISE SWOT}

Por motivo de dificuldade de verificação da circunstância da empresa em sua área de atuação, tanto quanto, da percepção da razão de seu posicionamento, pontos fracos e fortes e serem identificadas, ameaças e oportunidades que precisam ser levantadas, é neste momento que surgem ferramentas gerenciais de análise capazes de 
descrever a estrutura competitiva de uma empresa, dentre elas, pode-se citar a Matriz SWOT (Figura 2).

Figura 2 - Representação gráfica, da análise SWOT

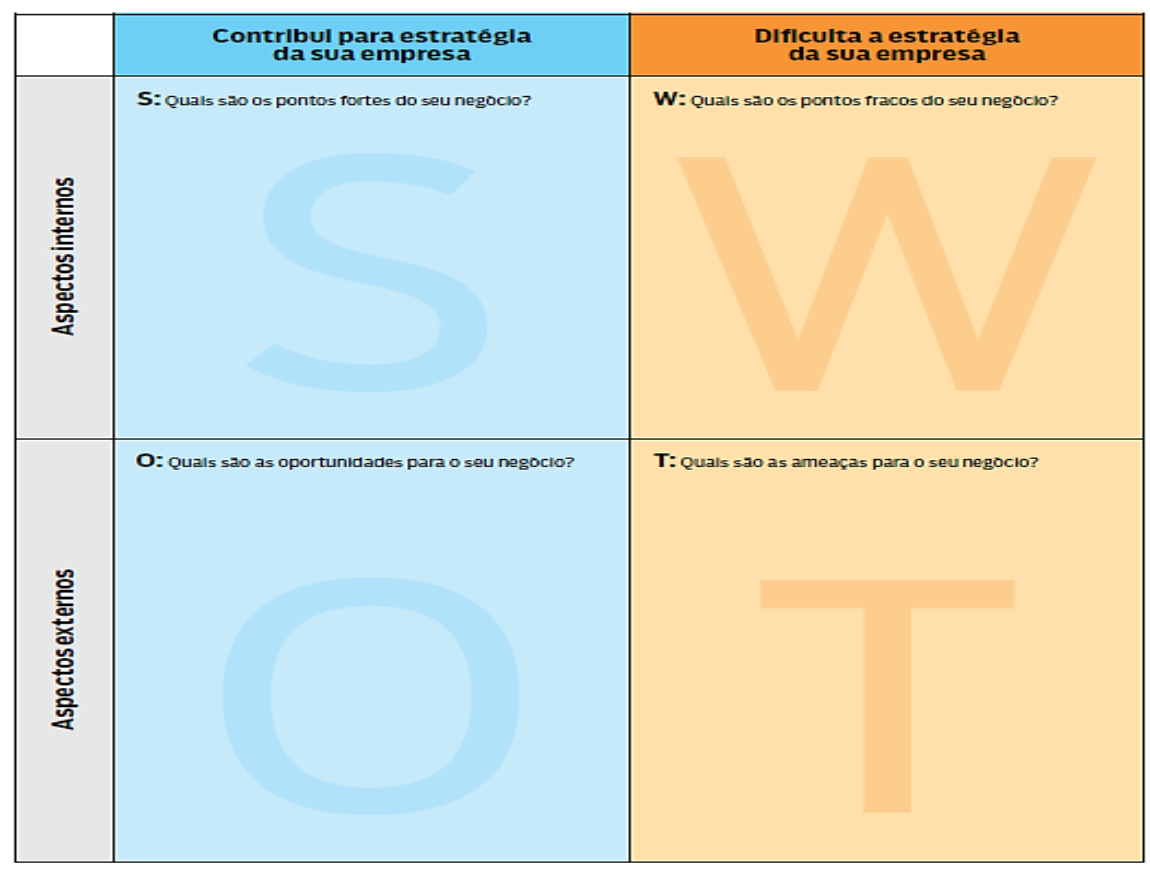

Fonte: SEBRAE (2011)

É um procedimento que se torna capaz de colaborar sem dúvidas com as empresas para qualificar suas vantagens e desvantagens, dando um posicionamento para os gestores através da visão de seus pontos fracos e pontos fortes. A técnica SWOT resume-se em retirar os pontos fracos em aéreas onde se encontram ameaças e consolidar os pontos fortes em áreas onde se detectam oportunidades.

Por esse motivo, este método é uma ferramenta da gestão empresarial usada por muitas empresas que comprova os obstáculos que devem ser superados e as circunstâncias favoráveis que precisam ser administradas. Segundo Marques (2005), o termo em inglês SWOT representa as iniciais das palavras Strenghts (forças), Weaknesses (fraquezas), Opportunities (oportunidades) e Threats (ameaças) e tem o intuito de investigar os pontos fortes e fracos de uma empresa, assim como as ameaças e oportunidades da própria frente no mercado em que trabalha. A tabela a prosseguir traz de forma exemplificativa algumas questões a serem considerados na análise SWOT: 
Tabela 2 - Aspectos a serem considerados na análise SWOT.

\begin{tabular}{|c|c|c|c|}
\hline \multicolumn{2}{|c|}{ AMBIENTE INTERNO } & \multicolumn{2}{|c|}{ AMBIENTE EXTERNO } \\
\hline Forças & Fraquezas & Oportunidades & Ameaças \\
\hline $\begin{array}{l}\text { Estratégia } \\
\text { poderosa }\end{array}$ & Falta de estratégia & Novos Clientes & $\begin{array}{l}\text { Novos concorrentes } \\
\text { potenciais fortes }\end{array}$ \\
\hline $\begin{array}{l}\text { Forte condição } \\
\text { Financeira }\end{array}$ & Instalações obsoletas & Expansão geográfica & $\begin{array}{l}\text { Perda de vendas para } \\
\text { Substitutos }\end{array}$ \\
\hline Marca forte & Balanço ruim & $\begin{array}{l}\text { Expansão da linha de } \\
\text { produtos }\end{array}$ & $\begin{array}{l}\text { Queda de crescimento do } \\
\text { Mercado }\end{array}$ \\
\hline $\begin{array}{l}\text { Líder de } \\
\text { mercado }\end{array}$ & $\begin{array}{l}\text { Custos mais altos que os } \\
\text { concorrentes }\end{array}$ & $\begin{array}{l}\text { Transferência de } \\
\text { habilidades para } \\
\text { novos produtos }\end{array}$ & $\begin{array}{l}\text { Mudanças nas taxas de } \\
\text { câmbio e políticas de } \\
\text { comércio }\end{array}$ \\
\hline $\begin{array}{l}\text { Tecnologia } \\
\text { própria }\end{array}$ & $\begin{array}{l}\text { Falta de habilidades } \\
\text { importantes }\end{array}$ & Integração vertical & $\begin{array}{l}\text { Regulação que aumenta os } \\
\text { custos }\end{array}$ \\
\hline $\begin{array}{l}\text { Vantagens de } \\
\text { custo }\end{array}$ & Lucros reduzidos & $\begin{array}{l}\text { Tirar mercado dos } \\
\text { concorrentes }\end{array}$ & $\begin{array}{l}\text { Crescimento do poder dos } \\
\text { clientes }\end{array}$ \\
\hline $\begin{array}{l}\text { Muita } \\
\text { propaganda }\end{array}$ & Problemas operacionais & Aquisição de rivais & Mudanças demográficas \\
\hline
\end{tabular}

Fonte: Serra, Torres e Torres (2004)

O estudo é feito em dois níveis, no ambiente externo e interno. O Ambiente externo entende as modificações que acontecem fora da empresa, entretanto podem abalar seu funcionamento e se caracterizam pelas ameaças ou oportunidades. $\mathrm{O}$ ambiente interno observa os pontos fortes e fracos e que deve ser controlados sempre. Este procedimento possibilita visualizar qual área tem um comportamento positivo diante do mercado e qual tem fragilidade e precisa melhorar.

\section{ANÁLISE DO AMBIENTE INTERNO - FORÇAS E FRAQUEZAS}

Somando os recursos destinados dentro da empresa, isto é, os recursos internos a respeito dos quais a empresa tem domínio e que deverão ser utilizados pela mesma para obtenção de seus objetivos, onde se incluem: recursos físicos, humanos, logísticos, operacionais, financeiros e mercadológicos, entre outros, definem-se como ambiente interno ou microambiente (PORTER, 2002).

Apesar de que é influenciável, apontam que a rumo da empresa trata-se de um trabalho difícil e que os stakeholders tenham traçado de forma clara o plano da empresa. Apesar disso, deduz-se que em geral os objetivos das empresas são decididos de forma estratégica, dispostos a gerar repercussões para os acionistas e atender as perspectivas dos demais stakeholders. De outra forma, é indispensável qualificar o comportamento 
da empresa no ponto de vista dos grupos de importância, no qual se abrangem: fornecedores, distribuidores, clientes e demais envolvidos com os negócios da empresa.

Uma ação é diferenciar as possibilidades atrativas do ambiente; outra é dispor a capacidades essenciais para desfrutar bem essas possibilidades. Desta forma, é indispensável à análise periódica das forças e fraquezas de cada negócio. O gerenciamento ou uma consultoria externa prevê as capacidades do marketing, finanças, de produção e atividade organizacional e relaciona cada motivo em termos de força (importante, sem importância e neutro) e de fraqueza (importante ou sem importância).

\section{ANÁLISE DO AMBIENTE EXTERNO - OPORTUNIDADES E AMEAÇAS}

Para Dornelas (2008), depois de identificada a missão da empresa e os gestores conhecerem os elementos micro ambientais importantes - consumidores, concorrentes, canais de distribuição, fornecedores. Devem ser analisadas as forças macro ambientais demográficas, econômicas, tecnológicas, políticas, legais, sociais e culturais - que afetam os processos organizacionais. A empresa deve estar preparada para rastrear tendências e desenvolvimentos importantes. Para cada tendência ou desenvolvimento, a administração precisa identificar as oportunidades e ameaças associadas.

A análise do ambiente externo é realizada em dois níveis: do macro ambiente e do ambiente setorial. Para Wright, Kroll e Parnell, (2000), apud Buccelli e Papadiuk, (2007), toda empresa existe dentro de uma complexa rede de interações ambientais. As empresas são afetadas por tendências econômicas, tecnológicas, socioculturais, políticolegais e mercadológicas. Juntas, essas tendências formam o macroambiente das empresas. Como essas interações são dinâmicas, suas constantes mudanças criam milhares de oportunidades e ameaças ou restrições para os gestores.

As oportunidades podem ser classificadas de acordo com a atratividade e a probabilidade de sucesso. A probabilidade de sucesso da empresa não depende apenas da força de seu negócio, das exigências básicas para ser bem-sucedida em seu mercado alvo, mas também das suas competências para superar seus concorrentes. A mera competência não constitui uma vantagem competitiva. A empresa de melhor desempenho será aquela que pode gerar o maior valor para o consumidor e sustentá-lo ao longo do tempo. 
A ameaça ambiental é um desafio decorrente de uma tendência ou desenvolvimento desfavorável que levaria a deterioração das vendas ou lucro. As ameaças devem ser classificadas conforme seu grau de relevância ou probabilidade de ocorrência. Para lidar com as ameaças, a empresa precisa preparar planos de contingência para enfrentá-las antes ou durante suas ocorrências, isso fará com que os gestores diminuam a possibilidade de que a organização venha a perder o foco em seus objetivos e deixem de alcançar as metas estipuladas.

\section{METODOLOGIA}

A abordagem cientifica utilizada para pesquisa é uma Pesquisa-ação, caracterizado como exploratório, descritivo e explicativo, em que se utiliza o método indutivo (DRESCH, 2015). Quanto ao delineamento, recorre-se à pesquisa bibliográfica, utilizando recursos tecnológicos de busca como instrumento para executar a pesquisa (GIL, 2008), neste caso, as bases de dados componentes do Portal de Periódicos da Coordenação e Aperfeiçoamento de Pessoal de Nível Superior (CAPES).

No presente estudo utiliza-se uma abordagem de natureza qualitativa, para classificar a pesquisa. Guimarães L., Martins e Guimarães P. (2004), descrevem os estudos qualitativos como mais flexíveis e particulares ao objeto de estudo, deste modo, esta pesquisa procura a partir de observações e de análises abertas, descobrir as tendências e os processos que explicam o como e o porquê das coisas.

Quanto aos objetivos da pesquisa pode-se determinar como sendo descritiva, que segundo Gil (2010) esta pesquisa é elaborada com a finalidade de detectar possível relação entre variáveis, Vergara (2013) complementa que a pesquisa descritiva "expõe características de determinada população ou de determinado fenômeno". Caracteriza-se também como um estudo de caso, pois pode ser "circunscrito a uma ou poucas unidades, entendidas essas como pessoa, família, produto, empresa, órgão público, comunidade ou mesmo país" (VERGARA, 2013).

$\mathrm{Na}$ aplicação da analise procedeu a técnica de coleta de dado primaria e secundaria. A informação primaria são capazes de ser colhida pela observação, entrevista e questionário. Já a informação secundaria sucedem de pesquisas bibliográficas. Os fatos primários da pesquisa vieram por meio de uma busca 
qualitativa, recorrendo da entrevista semiestruturada realizada junto à gestora e proprietária do Restaurante e Peixaria.

\section{RESULTADOS E DISCUSSÕES}

A compilação dos dados levantados através de entrevista com a gestora, com os concorrentes e com os fornecedores, bem como os dados obtidos através do questionário com os clientes, procedeu-se a análise das informações para a identificação das atividades organizacionais que deverão ser fortalecidas ou corrigidas, tanto em relação ao ambiente interno como externo.

\section{AMBIENTE INTERNO - PONTOS FORTES}

Espaço Agradável: durante o período de coleta de dados, observou-se que o empreendimento possui uma ótima estrutura para o atendimento dos seus clientes. $\mathrm{O}$ espaço externo foi construído e coberto recente.

Foi questionada a gestora de como havia conseguido fazer as modificações do empreendimento e a mesma disse que tinha pensado em colocar uma caixinha para sugestões, então os proprietários receberam as sugestões, de um espaço climatizado para as realizações de festa comemorativas, tais como, aniversário, noivado, chá de panela e etc. Além do espaço coberto que já tinha no local, foi feito um investimento para a compra de mesas e cadeiras onde foram utilizadas nas proximidades das arvores no local, proporcionando um ambiente ao ar livre.

O restaurante, mesmo que não possua um grande porte financeiro e espaço físico que possua, é necessário de qualquer modo estar agradável aos olhos dos clientes, dado que as situações da estrutura física, a cozinha, é o cartão de visitas de qualquer negócio do ramo. Por este motivo, foi apontado como um ponto forte em potencial, já que nas imediações não existem concorrentes bem estruturados.

Gestão participativa: á medida que foi exposto na entrevista à gestora declara que administra seu empreendimento exercendo que os seus colaboradores vejam os objetivos da empresa. Motiva a atuação ativa de seus funcionários nas recomendações de melhorias em todos os setores, a partir da cozinha até na criação dos pratos, inclusive 
a comunicação direta com os clientes, junto ao recolhimento de indicativos sobre o serviço prestado. Busca do mesmo modo compreender o ponto de vista dos funcionários em relação ás principais definições a serem tomado, ainda continuado com a palavra final, conforme descrição a seguir:

"Eles notam minhas alegrias, minhas dificuldades. Eu a todo o momento falo que eles estarão crescendo com a gente (...). Se vocês possuírem qualquer ideia no qual nós possamos melhorar, isto é em que ponto for, seja em atendimento ou em produto, (...) vocês podem falar, nós iremos analisar".

As considerações da gestora foram comprovadas pelas respostas de todos os funcionários ao questionário aplicado, confirmando as informações prestadas quanto à gestão participativa.

Preço Praticado: outro modo que a proprietária compreende como sendo um item encantador para a clientela foi o preço praticado através dos alimentos produzidos e servidos no Restaurante \& Peixaria. Quando argumentada se o seu produto seria capaz de ser vendido a um preço mais elevado, ela comenta:

“considero possível eu vender, mas não ia vender de tal maneira quanto se fosse ao preço que está atualmente. Ou seja, se eu for colocar caro, venderia, contudo venderia menos porque a gente trabalha para o bairro, onde tem pessoas humildes."

\section{AMBIENTE INTERNO - PONTOS FRACOS}

Atendimento ao Cliente: em diversos pontos da entrevista com a proprietária do empreendimento, esta foi objetiva em declarar que é uma de suas grandes preocupações quanto ao comportamento da empresa em ligação ao atendimento dos clientes. Entretanto, essa importância de possuir um ótimo atendimento ao cliente está sendo aplicado pelos proprietários, pois a maioria dos garçons não é funcionário direto do Restaurante \& Peixaria, e como até o presente momento do estudo, a mesma não possuía as suas missões, visão e valores da empresa, e sempre quando tinha um funcionário novo, não compreendia ao certo qual era o objetivo do negocio. 
“... a dedicação com o cliente é bastante significativo. (...) eu tenho que fazer com que o cliente saia contente, contudo essa MISSÃO estava apenas comigo, não requeria o mesmo para os meus funcionários, sempre recebo elogios como a minha recepção, no entanto sempre há uma reclamação dos funcionários...”.

Do modo que se pode analisar, para a gestora, o fator fundamental para a conservação sustentável do seu comercio é o atendimento ao cliente, entretanto isso não era cumprido com tanta excelência pelos funcionários. Desse modo essa informação foi confirmada no decorrer da pesquisa efetuada com os clientes.

Conforme a pesquisa (Gráfico1), 60\% dos entrevistados consideraram o atendimento por parte do proprietário "ótimo", $20 \%$ optaram por "muito bom", $15 \%$ afirmaram ser "bom" e só 5\% disseram que o atendimento é "ruim", o que comprova que o atendimento ao cliente é um ponto forte da empresa.

Gráfico 1 - Atendimento dos Proprietários.

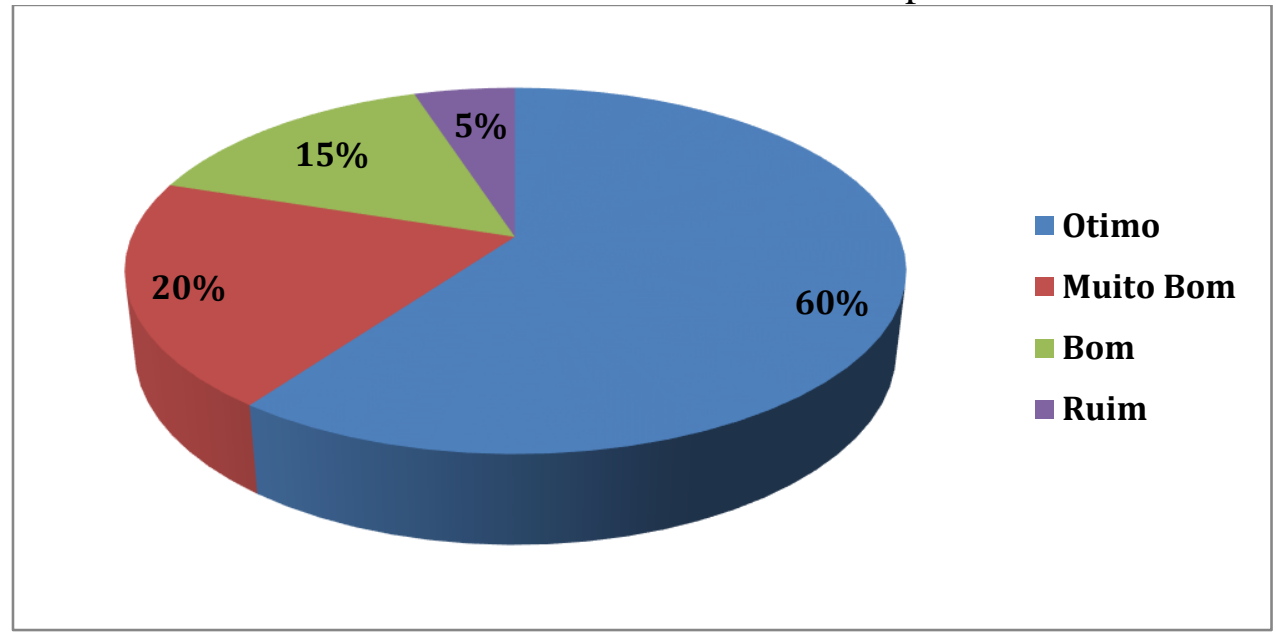

Fonte: Dados da pesquisa

No entanto a pesquisa sobre o atendimento dos funcionários relata que $55 \%$ consideram o atendimento "ruim", $20 \%$ optaram por "bom", $15 \%$ afirmaram ser "muito bom” e só $10 \%$ disseram que o atendimento é “ótimo” (Gráfico 2). 
Gráfico 2 - Atendimento dos Funcionários

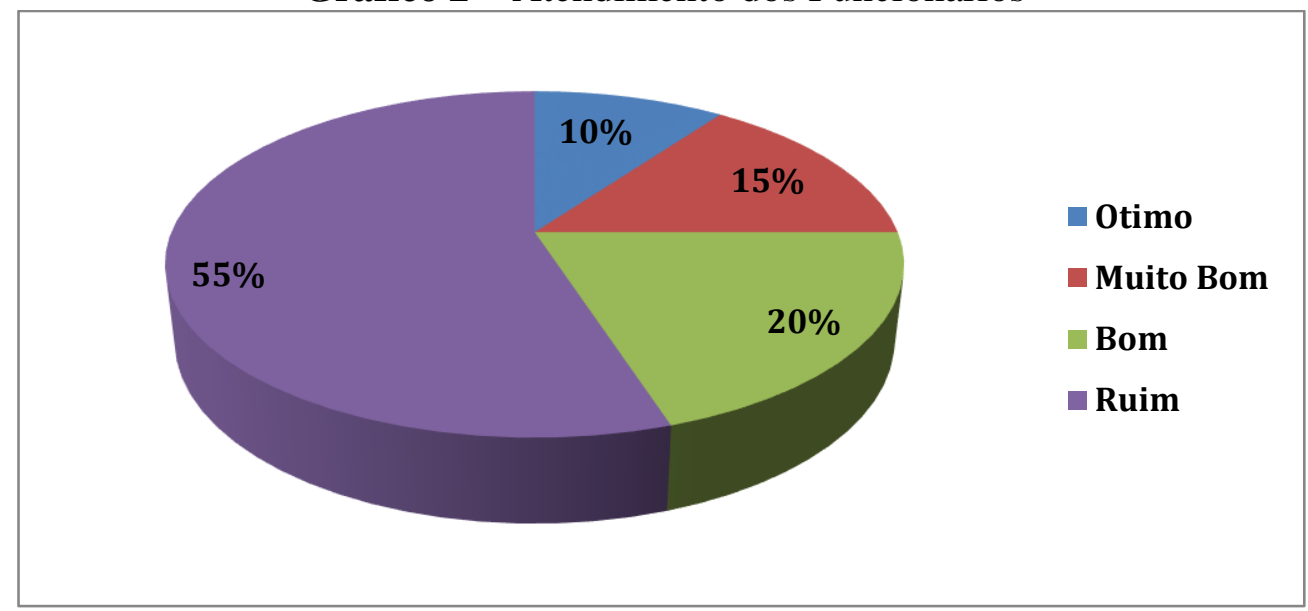

Fonte: Dados da pesquisa

Marketing: o estabelecimento, até o presente momento, não exerceu qualquer tipo de estratégia de marketing ou fez a simples produção de uma divulgação. Na percepção da gestora, o local é de grande beneficio para o negócio - localizado as margens do rio Cuiabá, e está posicionado em umas das mais tradicionais comunidades várzea-grandense, um dos grandes pontos culturais da cidade que dá acesso à culinária da região e atração turística, obtendo assim um fácil ganho para a conquista de vários clientes. Apesar disso, ao passar dos anos esse movimento turístico caiu cerca de $70 \%$ na região, e poucos turistas já ouviram falar sobre o Restaurante \& Peixaria.

A gestora mencionou que já pensou em confeccionar alguns folhetos, para distribuir nas redondezas, porém essa ação não foi concretizada. Relata também que parte da clientela são clientes antigos, de longa data:

"anteriormente havia pensado em criar uns panfletos para compartilhar nas empresas situadas na região, mas os recursos estão poucos e não deu..." “... boa parte dos nossos clientes é aqui da comunidade..." "...acredito que parte dos nossos clientes são os mais antigos, e que não frequenta o estabelecimento com tanta frequência..." "...foi feito um investimento para a divulgação do Restaurante \& Peixaria em um programa de TV, que será realizado todos os domingos de manhã, porém não obtivemos um ganho de novos clientes...".

Analisando os dados coletados da pesquisa, está dedução mostrou ser verdadeira, pois $95 \%$ das pessoas que estava na comunidade afirmaram não ser turista, apenas 5\% são da turista, e ainda que $90 \%$ da clientela pertencem à própria comunidade 
onde está localizada a empresa, e os outros $10 \%$ são de clientes que moram em bairros mais distantes (Gráfico 3).

Gráfico 3 - Estatística de Clientela.

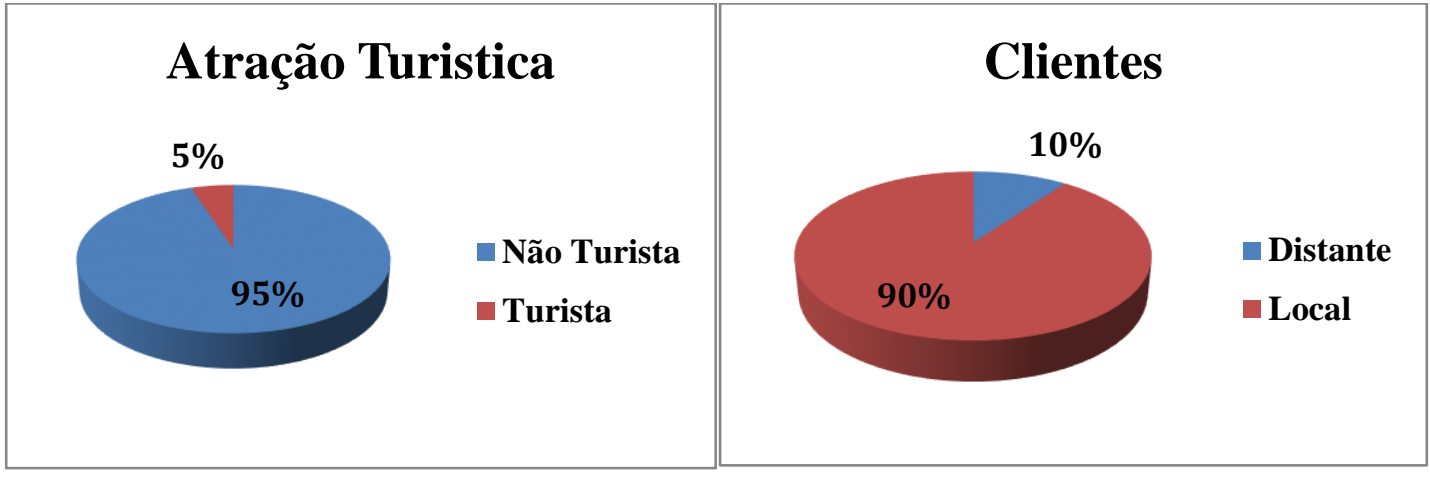

Fonte: Dados da pesquisa

Comprovou-se que a maior parte da clientela é oriunda do próprio bairro da empresa. A falta de divulgação entre os frequentadores e colaboradores da faculdade Atual e, também, maior inserção da empresa no próprio bairro é um dos motivos da não expansão do negócio. O que evidencia um ponto fraco a ser trabalhado.

Falta de Controle Financeiro: a redução da rentabilidade foi falada na entrevista pela proprietária e reconhecida pelos pesquisadores. A situação de estar sobrecarregada junto aos trabalhos diários da empresa, fez com que os apontamentos de gastos, a verificação das modificações de custo dos artigos componentes dos pratos a serem usados e a dedução do real ganho do restaurante fosse deixado para segundo plano.

Além disso, o que ofereceu para o agravo do cenário foi à ausência de conhecimento para o uso de programas computadorizados de controle financeiro na empresa. Ganhando o entendimento em relação a utilização desta ferramenta a gestora seria capaz de aproveitar melhor o período de trabalho dentro de uma tarefa e outra, proporcionando alguma brecha para os apontamento de gastos e receitas, controlando possíveis perdas ou investindo lucros desejados.

\section{AMBIENTE EXTERNO - OPORTUNIDADES}

Cativas os funcionários das empresas próxima do Restaurante \& Peixaria e assim cativar novos clientes: foi investigado que o empreendimento tem uma posição 
estratégica com relação ao bairro e a empresas localizadas nas proximidades. De acordo com a proprietária ela conhece seu público alvo, suas palavras:

"Os moradores do bairro e as famílias que busca a nossa comunidade para um dia de lazer, é que são no nosso público alvo".

Apesar disso, de acordo com a pesquisa no requisito localização dos clientes evidenciou-se que apenas $5 \%$ da clientela resulta de turista ou família em busca de lazer, e que os demais, 95\% da clientela moram nas proximidades da empresa, admitindo assim sua percepção quanto ao seu público alvo. Assim sendo, incluso no setor de marketing da empresa, existe a carência de divulgação para atrair novos clientes, desfrutando da boa localização da empresa, bem como, nos bairros próximos a fim de demandar maior público.

Ampliar a Variedade dos Produtos Ofertados: através da pesquisa no requisito variedade identificou-se que $60 \%$ da clientela classificou a variedade como Boa, e $30 \%$ como Muito Boa, e ainda $10 \%$ classificaram a variedade como ótima. Contudo com relação a novos produtos, na entrevista, a gestora citou que havia fornecido pastelzinho de peixe, bolinho e caldo com a entrada nos rodízios (Gráfico 4):

\section{Gráfico 4 - Variedades}

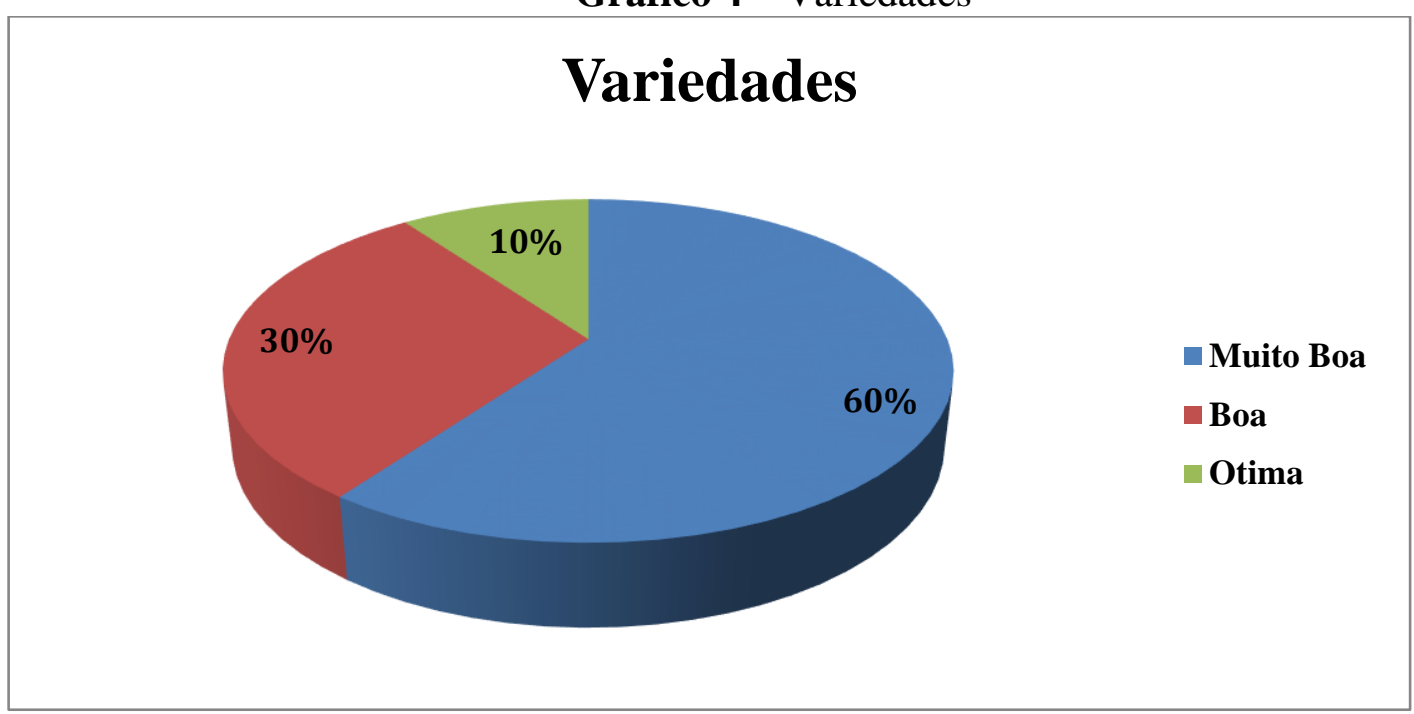

Fonte: Dados da Pesquisa

“... estávamos servindo pastelzinho, bolinho e caldo de peixe como entrada nos rodizio, mas não possuímos pessoas para produzir esses novos produtos na nossa cozinha assim teve que desfazer desses pratos, por sinal muito bem rentável e bem procurado..." 
Criação do Plano Estratégico para obter a Melhor Posição no Setor: o planejamento estratégico é capaz de alavancar no setor atendendo até mesmo uma colocação de destaque frente aos concorrentes. De acordo com as observações feitas pela equipe existem vários concorrentes nas proximidades no mesmo segmento, na entrevista com os concorrentes foi apontado que estes não se importam ou se envolvem com a presença da empresa em questão, e que não criaram nenhuma forma de planejamento ou pesquisa para o começo de novas empresas. O planejamento estratégico apareceria como diferencial desta empresa, que sairia na frente em demanda de ampliar sua fatia de mercado, levando-a a evoluir frente os concorrentes.

\section{AMBIENTE EXTERNO - AMEAÇAS}

Novos Entrantes: As empresas já constituídas ou em estruturação no mercado, sempre sofrem com a ameaça de novos entrantes, que serão instaladas próximas a eles ou ofertarão as melhores oportunidades para os consumidores. Os concorrentes apresentado pela gestora da empresa, não empregam nenhuma forma de investigação das necessidades, gostos e tendências dos clientes, é percebida uma necessidade em poucas oportunidades quando os próprios clientes reclamam. A entrevista com os concorrentes garante que os mesmos não faz o uso de nenhuma ferramenta para a análise da satisfação dos clientes e não exercita nenhuma forma de controle ou cadastro. Outro detalhe significativo é que nenhum deles se assegura alerta sobre as atividades dos concorrentes. Contudo o resultado da pesquisa aponta que os concorrentes atuais não se preocupam com o seu espaço no mercado, sendo assim, facilitando a abertura de espaço para novos entrantes bem mais estruturados.

Falta de conhecimento sobre Vigilância Sanitária: Poucas barreiras são de ordem governamental, não que sejam ruins, apesar disso trazem transtornos, em virtude da ausência de conhecimento por parte da gestão sobre as obrigações da vigilância sanitária, conforme a entrevista a gestora disse:

\footnotetext{
"eles requisitaram umas separações com tela pra não passar insetos, (...), eles irão retornar, porém no geral da cozinha não falaram nada, quando eles voltarem iremos ver o que eles vão pedir".
} 
Diante disso na entrevista constata-se que a gestora não se isenta de praticar as exigências, mas sim que não possui das informações necessárias para a execução dessas exigências, o que pode se transformar em uma ameaça para a permanência da empresa.

Concorrência instalada nas imediações: consideram-se os concorrentes da Peixaria os que oferecem produtos semelhantes aos oferecido pela empresa. Os concorrentes que fornece os mesmo pratos estão todos localizados no distrito de Bonsucesso. Sendo assim, fica considerado uma alta ameaça para o negocio.

\section{QUESTÕES ESTRATÉGICAS}

Por meio do recolhimento de dados realizado no Restaurante \& Peixaria, foram elevados e relacionados os elementos da Matriz SWOT, através destes então foi realizada a análise de ambientes, argumentando impactos e inter-relações que compõem a matriz.

\section{PONTOS FORTES X PONTOS FRACOS}

Espaço Agradável X Marketing: Destacar a qualidade e ampliação do espaço junto ao marketing. A conclusão da pesquisa apontou que o ambiente do Restaurante \& Peixaria é um ponto forte, já que os índices da pesquisa apontam que $60 \%$ destes consideram o ambiente "ótimo", 20\% e 15\% consideram o ambiente "muito bom" e "bom", e apenas 5\% o classificou como ruim. Este diferencial é uma condição importante no trato com clientes, quando a estratégia envolve desenvolver o marketing da empresa. Esta sugestão busca em apostar numa campanha de marketing, anunciando o belo espaço para a realização de eventos da clientela no próprio ambiente.

Gerenciamento Comunicativo X Atendimento ao Cliente: Realçar a comunicação interna exercendo para um ótimo atendimento ao cliente. Do mesmo modo, na pesquisa foi exposto que ocorre o gerenciamento comunicativo na empresa, portanto, não foi realizado com os funcionários nenhum tipo de treinamento de atendimento ao cliente deixando esse quesito com um ponto fraco para a peixaria. A 
medida sugerida para os proprietários é a realizado e treinamentos, onde será realizado por meio de e-book onde deixei disponíveis para os proprietários.

Preço praticado X Falta de Controle Financeiro: Proporcionar a exposição do preço dos produtos à medida que é desenvolvida uma educação de controle financeiro. A gestora declara que os preços são baixos em comparação com os concorrentes, e os clientes comprovam através da pesquisa, no entanto, a gestora afirma que a empresa não obteve nenhum tipo de controle financeiro, nem por sistema ou planilha que seja. A proposta foi em aplicar uma planilha de controle financeiro. Buscando na internet um software com versão gratuita onde terá o controle do atendimento e financeiro.

\section{OPORTUNIDADE X AMEAÇAS}

Cativar novos Clientes $\mathrm{X}$ Novos Entrantes: Adquirir os funcionários da proximidade tendo um ganho competitivo com os novos entrantes. Na proximidade do Restaurante \& Peixaria há diversas empresas, com uma quantidade considerável de funcionário, proporcionando assim a meta de cativar eles como novos clientes. A gestora fez uma visita nessas empresas, levando a proposta que os funcionários da mesma obtêm um desconto de $10 \%$ no almoço, comparecendo no Restaurante \& Peixaria basta informar que é funcionário de tal empresa para adquirir o desconto. Levou a proposta também de um dia da semana servi a refeição na empresa e ficou acordado que a ultima sexta do mês o Restaurante \& Peixaria fornecera marmitas na empresa com o preço acordado entre eles. A aplicação dessa proposta é um diferencial que determina manter empresa no mercado, de forma competitiva com os novos entrantes, no entanto ocorrerá por outro lado o aumento da procura pelo motivo da divulgação, assim sendo é necessário preparar-se para acompanhar essa mudança.

Variedade de Produtos X Elevada Concorrência instalados nas imediações: Divulgar a ampliação da variedade de produtos oferecidos. Na pesquisa feita com os clientes foi interrogado o motivo pelo qual estes visitam a concorrência, a variedade de produtos foi o segundo maior indício com $23 \%$ dos clientes, já na questão o que você adoraria que houvesse no Restaurante \& Peixaria, 30\% opinaram que gostariam que voltassem a servir os pasteizinhos, bolinho e caldo de peixe como entrada do rodizio. 
A proprietária havia referido sobre isso na entrevista alguns meses atrás, que estava começado a servir os pasteizinhos, bolinho e caldo de peixe como entrada do rodizio, e que era bem procurado. Contudo foi necessário desistir devido à falta de colaboradores para produzir esses novos pratos. Diante da grande ameaça de concorrentes instalados nas imediações do Restaurante \& Peixaria, e para absorver o aumento da demanda seria necessário investir em uma nova contratação, essa idealização é acessível, pois os pasteizinhos, bolinhos e caldos já haviam sido realizados na empresa e foi visível o retorno.

Criação do Plano Estratégico para obter melhor posição no setor X Falta de conhecimento sobre Vigilância Sanitária: Elaboração de um Plano Estratégico incorporado ao Planejamento de conhecimento sobre a Vigilância Sanitária. A empresa em nenhum momento se interessou sobre o plano estratégico e junto conquistar o conhecimento sobre Vigilância Sanitária. Foi proposto o uso da ferramenta estratégica que irá trabalha para que empresa tenha diversos benefícios, dentre eles o consume de divulgação, que a empresa não usa para atrair novos clientes, e o emprego de uma disciplina de desempenho de tarefas e processos de atendimento que visa a redução da insatisfação do cliente, de custos, o aumento da qualidade e a obtenção da eficiência e eficácia e, sobretudo o controle financeiro.

\section{CONCLUSÃO}

O presente estudo buscou elaborar uma proposta de plano estratégico para o Restaurante \& Peixaria. Apresentou-se, na organização a falta de um plano de crescimento, fundamental à empresa, que possui uma capacidade de crescimento no mercado em que está inserida.

Com o objetivo para realizar o trabalho, foi essencial traçar os seguintes elementos: reconhecimento da missão, definição da visão, valores e análise do ambiente (interno e externo), responsável pela listagem das ameaças, oportunidades, fraquezas e forças que envolvem o contexto da empresa.

Após este levantamento foi elaborado as questões estratégica, interligando os fatores fortes e fracos, oportunidades e ameaças e determinando assim os objetivos estratégicos fundamentais, que encerram a proposta deste trabalho. 
No cumprimento deste estudo buscou-se abordar, de uma maneira franca, fácil e objetiva o plano estratégico almejado, para que seja de simples e rápido a implantação pela empresa, na suposição de ser praticado.

Por fim, importante salientar que, a proposta provoca em modificações consideráveis em seus processos, e no vínculo da relação com o mercado, que apresenta pela postura dos colaboradores, até a obtenção de maior credibilidade, e decorrente ao aumento do quadro de clientes, que fazem o mercado em que o Restaurante \& Peixaria estão inseridos.

\section{REFERÊNCIAS}

BUCCELLI, Dalton O.; POPADIUK, Silvio. Integração dos ativos intangíveis no processo de planejamento estratégico: uma revisita à matriz SWOT. In: FACEF PESQUISA v.10. n.3. São Paulo: 2007.

CAPES. Portal de Periódicos da Capes. Disponível em:. Acesso em: 01 mar. 2018.

CONFEDERAÇÃO NACIONAL DO COMÉRCIO DE BENS, SERVIÇOS E TURISMO. A competitividade nos setores de comércio, de serviços e do turismo no brasil: perspectivas até 2015. Brasília: CNC; SEBRAE, 2008. 120p

COSTA, E. A., Gestão Estratégica. São Paulo: Saraiva 2004

DORNELAS, J. C. A.; TIMMONS, J.; ZACHARAKIS, A.; SPINELLI, S. . Planos de negócios que dão certo. 1. ed. Rio de Janeiro: Campus / Elsevier, 2007.

DRUCKER, Peter F. Introdução à administração. São Paulo: Pioneira, 1984.

DORNELAS, José Carlos de Assis. Empreendedorismo: transformando ideias em negócios: $3^{\mathrm{a}}$ ed. Rio de Janeiro: Editora Elsevier, 2008.

DRESCH, A. et al. Design Science Research: método de pesquisa para avanço da ciência e tecnologia. Porto Alegre: Bookman, 2015. 204p.

GIL, A. C. - 2008. Como elaborar projetos de pesquisa. São Paulo: Atlas.

GUIMARÃES, Liliana Andolpho M.; MARTINS, Daniela de Almeida; GUIMARÃES, Patrícia Magalhães. Os métodos qualitativo e quantitativo: similaridades e complementaridade. In: GRUBITS, Sonia; NORIEGA, José Angel Vera. Método Qualitativo: epistemologia, complementariedade e campos de aplicação. São Paulo: Vetor, 2004.

MARQUES, Neiva de A. Teoria da Administração I. 2. Ed. Reimp. Florianópolis: Departamento de Ciências da Administração, UFSC, 2012. 
PORTER, Michael. Estratégia Competitiva: Técnicas para Análise de Indústrias e da Concorrência. Rio de Janeiro: Campus, 2002.

SERRA, Fernando A. Ribeiro; SERRA, Maria Cândida S. Torres.; TORRES, Alexandre Pavan. Administração Estratégica - Conceitos, Roteiro Prático e Casos. 1. ed. Rio de Janeiro: Reichmann \& Affonso Editores, 2004.

KOTLER, Philip. Administração de Marketing. 10 ed. São Paulo: Prentice Hall, 2003.

SERRA, F. et al. Administração Estratégica: conceito, roteiro prático e casos. 4 ed Florianópolis: Insular, 2009.

OLIVEIRA, D. P. R. Planejamento Estratégico: conceitos, metodologia e práticas. 31. ed. São Paulo: Atlas, 2013.

TAVARES, M. C. Gestão Estratégica. 3 ed São Paulo: Atlas , 2010.

WRIGHT, P .; KROLL, M .; PARNELL, L. Administração estratégica: conceitos. São Paulo: Atlas, 2000.

VERGARA, Sylvia Constant. Projetos e relatórios de pesquisa em administração. 14. ed. São Paulo: Atlas, 2013.

\section{Recebido em: 10/10/2021}

Aprovado em: 20/11/2021 